\title{
Motivations for avoiding wheat consumption in Australia: results from a population survey
}

\author{
Sinéad Golley ${ }^{1}$, Nadia Corsini ${ }^{1}$, David Topping ${ }^{1}$, Matthew Morell ${ }^{2}$ and Philip Mohr ${ }^{3, *}$ \\ ${ }^{1}$ CSIRO Food Futures National Research Flagship, Adelaide BC, South Australia, Australia: ${ }^{2}$ CSIRO Food Futures \\ National Research Flagship, Canberra, Australian Capital Territory, Australia: ${ }^{3}$ School of Psychology, University of \\ Adelaide, Adelaide, SA 5005, Australia
}

Submitted 8 August 2013: Final revision received 28 February 2014: Accepted 13 March 2014: First published online 17 April 2014

\begin{abstract}
Objective: To assess the prevalence of and explanations for wheat avoidance, including reported symptoms, diagnoses and information sources influencing the decision to avoid wheat, and to investigate potential psychological predictors of this behaviour.

Design: Cross-sectional population survey.

Setting: The study was conducted in Australia, using a nationwide postal omnibus survey.

Subjects: Adults aged 18 years and over ( $n$ 1184; 52.9\% female) selected at random from the Australian Electoral Roll.

Results: With cases of stated and suspected coeliac disease (1.2\%) excluded, $7 \cdot 3 \%$ of the sample reported adverse physiological effects, predominantly gastrointestinal, that they associated with wheat consumption. Few among this group (5.7\%) claimed a formally diagnosed intolerance or allergy requiring avoidance of wheatbased foods. Symptomatic wheat avoidance was highly correlated with dairy avoidance and predicted by gender (female), lesser receptiveness to conventional medicine and greater receptiveness to complementary medicine, but not by neuroticism, reasoning style or tendency to worry about illness.

Conclusions: The data indicate that many adult Australians are consciously avoiding consumption of wheat foods, predominantly without any formal diagnosis. Reported symptoms suggest a physiological but not allergenic basis to this behaviour. Questions to be answered concern whether symptoms are attributed correctly to wheat, the agents (wheat components, dietary factors or additives) and physiological mechanism(s) involved, the nutritional adequacy of avoiders' diets, and the clinical and psychosocial processes that lead a substantial number of adults to avoid consuming wheat (or any other dietary factor) apparently independently of a medical diagnosis.
\end{abstract}

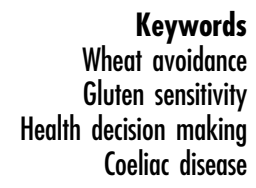

Wheat is an important cereal grain, and refined wheat-based products provide a significant fraction of daily energy intake (as starch) in the USA and similar countries ${ }^{(1)}$. Wholegrain cereals make an additional contribution to health by supplying a range of other nutrients including protein, fibre, vitamins and minerals. In Australia, cereals (principally wheat) supply over $30 \%$ of the total dietary fibre intake ${ }^{(2)}$. It is well known that wheat can also elicit clinically important adverse reactions in some individuals, of which coeliac disease is the most widely recognised. Coeliac disease is a serious autoimmune disorder triggered by gluten, a class of proteins (including gliadins and glutenins) contained in wheat grains, and similar proteins found in barley (hordeins) and rye (secalins) $)^{(3,4)}$. The symptoms of coeliac disease include diarrhoea, abdominal distension, failure to thrive (in children) and weight loss. Atypical coeliac disease is characterised by extraintestinal manifestations, such as anaemia, short stature, arthritis, osteoporosis and infertility ${ }^{(5)}$. Wheat is also recognised as a potential food allergen ${ }^{(6)}$, with ingestion in affected individuals eliciting immediate typical IgE-mediated reactions including urticaria, angioedema, bronchial obstruction, nausea and abdominal pain, or, in severe cases, systemic anaphylaxis. Delayed hypersensitivity symptoms may appear about $24 \mathrm{~h}$ after wheat ingestion and include gastrointestinal symptoms and exacerbation of atopic dermatitis $^{(7)}$.

While both coeliac disease and true wheat allergy occur relatively infrequently, with estimated prevalence rates of $1 \%$ or less in the Australian population ${ }^{(8)}$, research suggests that a much greater proportion of the population may be 
avoiding wheat- or gluten-based products than would be expected from these figures ${ }^{(9-11)}$. This dietary trend is suggested in the burgeoning availability of gluten-free food products $^{(9)}$ and the increasing popularity of gluten-free grains $^{(11)}$. Concurrent with this is research activity in the USA, Europe and other parts of the world on possible physiological explanations for the avoidance of wheat, on the premise that it is symptom-driven. Initial explanations included increased prevalence of undiagnosed coeliac disease $^{(5)}$ and broadening the spectrum of gluten-related disorders to include the possibility of non-coeliac gluten sensitivity $^{(9,12-17)}$. Recently other, non-gluten, constituents of wheat have been implicated in the triggering of symptoms in non-coeliac individuals: in particular, the intestinal malabsorbtion of short-chain carbohydrates (fermentable oligo-, di- and monosaccharides and polyols (FODMAPS $))^{(18,19)}$ and the potential contribution of $\alpha$-amylase/ trypsin inhibitors ${ }^{(20)}$.

This focus on identifying ways in which the consumption of wheat might trigger symptoms in some people casts little direct light on the practice of wheat avoidance and the basis for it. We report an Australian population survey in which we examined the prevalence of and reported reasons for wheat avoidance. We also asked about symptoms and diagnoses leading to the decision to avoid wheat and investigated the possible association of wheat avoidance with other health conditions and behaviours. Among the behaviours considered was avoidance of dairy foods, as an analysis of market research attitudinal data had shown rejection of wheat and dairy products to be highly correlated (B Bajka, D Topping, P Mohr et al., unpublished results). We also examined possible predictors of the behaviour, including whether attitudes to different treatment approaches and certain psychological characteristics - specifically an anxious disposition, tendency to worry about illness and a propensity for a less analytical and/or more intuitive reasoning style - may predispose some individuals to avoid wheat.

\section{Method}

\section{Study design}

We employed a cross-sectional survey design using data obtained through the Commonwealth Scientific and Industrial Research Organisation (CSIRO) Food and Health Survey.

\section{Participants}

Three thousand surveys were distributed to a proportional stratified random sample of eligible voters selected from the eight States and Territories of Australia (the strata) by the Australian Electoral Commission. One hundred and thirty-three surveys were returned uncompleted due to death ( $n$ 2), infirmity ( $n$ 11), language difficulties ( $n 2$ ) or unknown whereabouts of the addressee ( $n$ 118), and 1184 completed forms were returned (a response rate of $41.3 \%)$. The sample consisted of adults aged 18 years and over: 527 males (44.5\%), 626 females (52.9\%) and thirtyone not specified (2.6\%); mean reported age was 51.64 (SD 16.78) years. Observed gender and age distributions were significantly different from population estimates $\left(\chi^{2}(1, n\right.$ 1148 $)=6 \cdot 02, P=0.01 ; \chi^{2}(6, n$ 1144 $)=149 \cdot 78$, $P<0.01$ respectively), with women and older people overrepresented. The data were weighted to adjust for this in the calculation of population prevalence estimates but not in other analyses.

\section{Procedure}

The CSIRO Food and Health Survey was a 200-item postal omnibus survey conducted between December 2010 and February 2011 assessing attitudes and behaviours in response to health, diverse foods and food characteristics, and diet, as well as more general attitudes and personal characteristics. A subset of these items, spread across seven labelled sections of the survey, provided the data for the present study; this manner of obtaining data for multiple studies protects against signalling to participants specific hypotheses of interest. A letter informing potential participants of the survey was sent one week before distribution of the survey forms. A follow-up letter was sent to the entire sample two weeks after survey distribution. This second letter served both to thank those individuals who had already completed the survey and to remind those who had yet to respond that there was still time to participate. The survey package included a replypaid envelope and a CSIRO-labelled ballpoint pen. Participation was anonymous. The study was conducted according to the guidelines laid down in the Declaration of Helsinki and all procedures involving human subjects were approved by the CSIRO Human Research Ethics Committee.

\section{Variables}

In a section of the survey labelled 'Avoidance of wheat and/ or dairy products', participants were asked whether they avoided eating or drinking foods or beverages containing wheat. Those who answered in the affirmative were asked: (i) whether they avoided all or only certain wheat products and, if so, to specify which; (ii) to state their main reason for avoiding consumption of wheat products; (iii) to identify any reaction experienced to wheat consumption from a list of eighteen physical and psychological symptoms including typical gastrointestinal and allergic reactions and disturbances of mood; (iv) to indicate on a three-point scale ('not at all', 'somewhat', 'very much') the extent to which each of seven medical or non-medical sources of recommendation or information had contributed to their decision to avoid wheat products; and (v) whether their avoidance was in response to a formally diagnosed condition and, if so, to specify the condition. An otherwise identical set of questions addressed the avoidance of dairy products; of 
these, only responses to the initial filtering question were used in the present analyses.

Other sections of the survey contained questions relating to health and diet, as well as attitudinal and other psychological measures. The following measures were used for the present study.

Neuroticism, a personality dimension characterised by proneness to anxiety and other negative emotions, was measured with the NEO-N Domain ${ }^{(21)}$. Participants rated nine statements (e.g. 'I often feel blue', 'I panic easily') on a five-point scale, where $1=$ 'completely false' and $5=$ 'completely true' (mean $=2 \cdot 41, \mathrm{SD}=0 \cdot 69, \alpha=0 \cdot 80)$. A tenth item ('I seldom feel blue') was omitted to avoid redundancy.

We used the ten-item version of the Rational-Experiential Inventory (REI) ${ }^{(22)}$, which comprises five items drawn from the Need for Cognition Scale ${ }^{(23)}$ and five items from the Faith in Intuition Scale ${ }^{(22)}$, each item scored on a five-point scale from 'completely false' to 'completely true'. Higher subscale scores represent increased reliance on analytical (mean $=3.51, \mathrm{SD}=0.82, \alpha=0.75$ ) and intuitive reasoning (mean $=3 \cdot 77, \mathrm{SD}=0 \cdot 74, \alpha=0 \cdot 86$ ), respectively.

In a section addressing general health information, participants were asked to indicate whether they had ever been diagnosed with any of a list of twelve conditions, including bowel disorders and various allergies. We measured worry about illness with four items from the Whitely Index for the assessment of hypochondriasis (e.g. 'Do you often worry about the possibility that you have got a serious illness?') ${ }^{(24)}$. Responses were made on a five-point scale, where $1=$ 'not at all' and $5=$ 'very much' (mean $=2 \cdot 52, \mathrm{SD}=0 \cdot 87, \alpha=0.82$ ), as previously used by Barsky et $a l{ }^{(25)}$. In the same section of the survey, we asked respondents how likely they would be to take each of ten actions 'for health matters of various kinds'. The actions included 'Consult a doctor', 'Consult a naturopath' and 'Take supplements or vitamins'; responses were made on a scale from $1=$ 'definitely not' to $7=$ 'definitely'. Suitability of the data for factor analysis was confirmed by a value of 0.74 on the Kaiser-Meyer-Olkin measure of sampling adequacy and a significant Bartlett's test of sphericity $(P<0.001)^{(26)}$. Parallel analysis, using a Monte Carlo analysis with 1000 replications, suggested the extraction of two factors. Following principal axis factoring with varimax rotation, we calculated scores on two subscales, which we named 'Receptiveness to conventional medicine' (four items: mean $=5.30, \mathrm{SD}=1 \cdot 07, \alpha=0.75$ ) and 'Receptiveness to complementary and alternative medicine' (six items: mean $=3 \cdot 74, \mathrm{SD}=1 \cdot 12, \alpha=0 \cdot 71$ ).

\section{Statistical analyses}

Prior to analyses, the pattern of missing data for the continuous variables was investigated with the Missing Values Analysis module in IBM SPSS Statistics 20. Little's MCAR test ${ }^{(27)}$ showed that the data were missing completely at random $\left(\chi^{2}=28701.40, \mathrm{df}=28818, P=0.69\right)$; consequently, missing values were imputed using the expectation maximization (EM) algorithm. This method replaces missing values with iterative maximum likelihood estimations based on the available data. Descriptive statistics were calculated to provide frequency distributions and cross-tabulations of key variables. Responses to the symptom check-list were subjected to cluster analysis to determine if there were commonalities in the pattern of symptoms reported that could be used to group wheat avoiders meaningfully. The $\chi^{2}$ test of independence and Fisher's exact test, as appropriate ${ }^{(28)}$, were used to examine associations between categorical variables. Predictors of wheat avoidance were assessed by means of multivariable logistic regression.

The statistical software package IBM SPSS Statistics 20 was used for all analyses.

\section{Results}

\section{Preliminary analyses}

Of all participants who returned completed questionnaires, 126 (10.6\%; 10.7\% age- and gender-weighted) indicated that they were currently avoiding products containing wheat $(6.1 \%$ of all males, $14.5 \%$ of all females and three of undisclosed gender).

This number included twenty-five $(2.1 \% ; 2.6 \%$ weighted) who reported avoiding wheat for reasons other than health-related symptoms. Explanations given included having a family member with coeliac disease ( $n$ 4), body weight-related factors $(n 5)$, personal taste or preference ( $n$ 5) and other reasons ( $n$ 11). The remaining 101 wheat avoiders $(8.5 \%)$ reported experiencing at least one negative reaction to the consumption of wheat-based products. From a cluster analysis of reported symptoms, we identified two distinct symptom clusters in this group: one containing the considerable majority of cases ( $n$ 92); and the other ( $n$ 9) comprising a number of highly symptomatic cases, each reporting between eight and thirteen symptoms. The type and number of symptoms reported by this second cluster typically reflected those commonly associated with coeliac disease (i.e. fatigue, diarrhoea, constipation, bloating, abdominal pain, nausea or vomiting, irritability). Moreover, five individuals in this second cluster reported having been formally diagnosed with coeliac disease, and we therefore classified all nine cases as putative coeliac patients. We extended this classification to include five cases from the larger cluster who also reported a diagnosis of coeliac disease (total $n 14 ; 1.2 \% ; 1.1 \%$ weighted). We excluded these fourteen cases for which we had reasonable grounds to suspect coeliac disease from further analysis. Figure 1 outlines the process of classifying participants.

\section{Main analyses}

All subsequent analyses focused on the remaining eightyseven $(7 \cdot 3 \% ; 7.0 \%$ weighted) symptomatic wheat avoiders. Of this group, forty-eight (55.9\%) nominated physical 


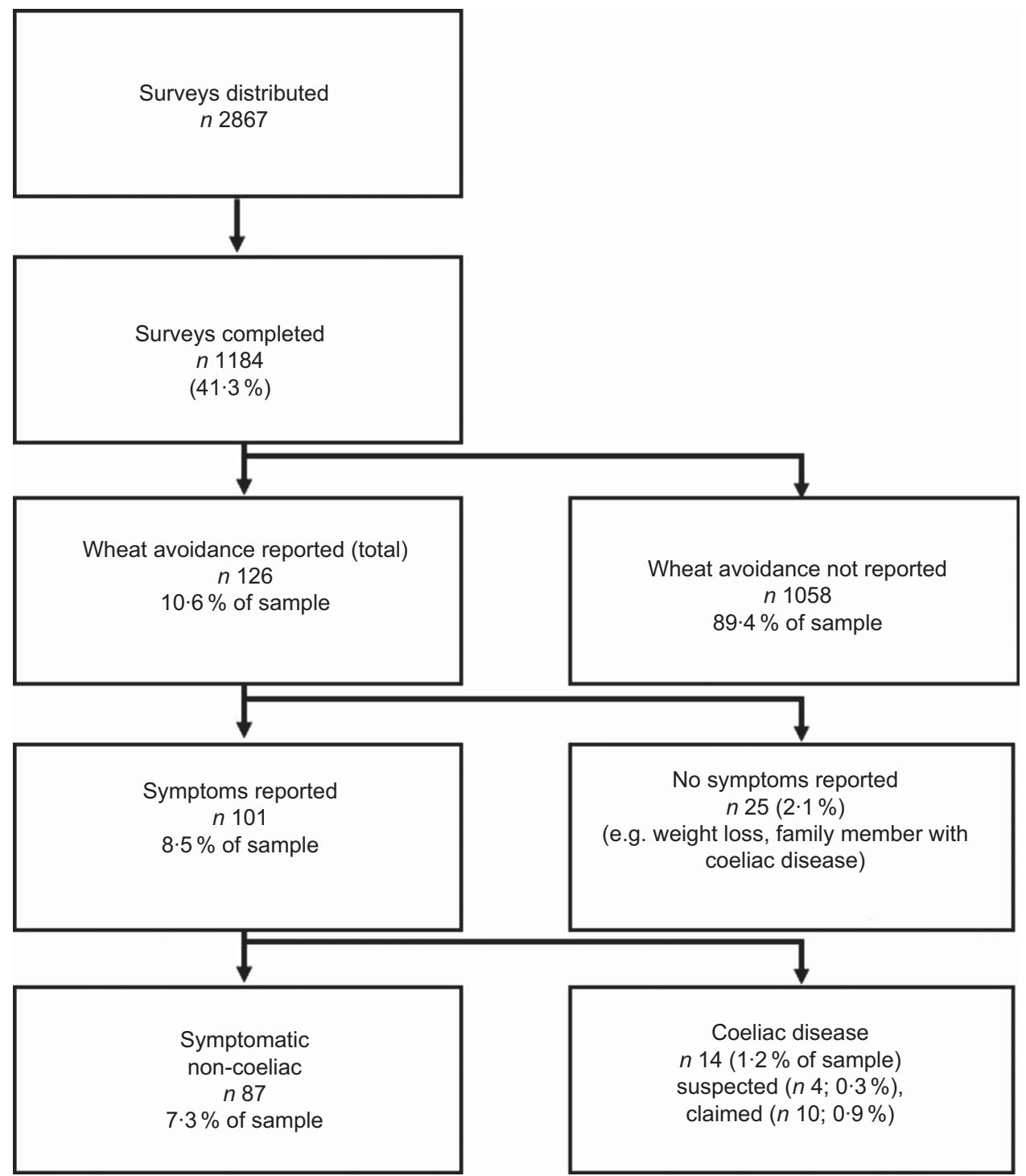

Fig. 1 Flowchart of the classification of self-reported wheat avoiders; CSIRO Food and Health Survey, Australia, December 2010-February 2011

reactions as their main reason for avoiding wheat, thirteen $(14.9 \%)$ nominated an intolerance or allergy, and ten $(11.5 \%)$ gave no reason. Six $(6 \cdot 8 \%)$ of the references to intolerance or allergy specified gluten as the trigger; there were no other references to gluten. Table 1 shows the distribution of symptomatic wheat avoiders by sex and extent of avoidance. Partial wheat avoidance was reported more frequently than full avoidance, and prevalence of avoidance was greater in women $(11.0 \% ; 10.8 \%$ weighted) than men (3.0\%), $\chi^{2}(1, n 1153)=26 \cdot 72, P<0 \cdot 001$. When partial avoiders ( $n$ 64) were asked to list which wheat products they were avoiding, the most frequently nominated foods were bread $(44.9 \%)$, pasta $(16.3 \%)$, breakfast cereals (14.3\%), unspecified refined white flour products (12.2\%) and cakes, biscuits or doughnuts (10.2\%).

Among the eighty-seven symptomatic wheat avoiders, the most commonly reported reactions were bloating or wind', 'stomach discomfort or cramps' and 'feeling sluggish and tired'. Only $14.9 \%$ of avoiders did not report either bloating or cramps. Table 2 lists the frequency of occurrence of all eighteen symptoms; these did not differ significantly between self-reported complete and partial avoiders. Only $16 \cdot 1 \%$ ( $n$ 14) of symptomatic wheat avoiders reported having a formal diagnosis that required them to avoid wheat. When they were asked to specify the condition, responses occurring more than once were gluten intolerance ( $n 3 ; 3.4 \%$ ), irritable bowel syndrome ( $n$ 3; 3.4\%), diverticulitis ( $n 2 ; 2.3 \%$ ) and (unspecified) allergy ( $n 2 ; 2 \cdot 3 \%$ ).

Table 3 shows the frequency of past diagnoses reported by the eighty-seven self-identified symptomatic wheat avoiders and the rest of the survey sample (with the fourteen putative coeliac cases excluded). Symptomatic wheat avoiders were significantly more likely to report a 
Table 1 Representation in the sample ( $n$ 1184) of symptomatic wheat avoiders by gender and degree of avoidance; CSIRO Food and Health Survey, Australia, December 2010-February 2011

\begin{tabular}{|c|c|c|c|c|c|c|c|c|}
\hline & \multicolumn{2}{|c|}{ Males (\%) } & \multicolumn{2}{|c|}{ Females (\%) } & \multicolumn{2}{|c|}{ Unknown gender } & \multicolumn{2}{|c|}{ Total } \\
\hline & $n$ & $\%$ & $n$ & $\%$ & $n$ & $\%$ & $n$ & $\%$ \\
\hline Complete avoiders & 6 & 0.5 & 25 & $2 \cdot 1$ & 0 & 0.0 & 31 & 2.6 \\
\hline Partial avoiders & 7 & 0.6 & 40 & 3.4 & 2 & 0.2 & 49 & $4 \cdot 1$ \\
\hline Extent of avoidance not specified & 3 & 0.2 & 4 & 0.3 & 0 & 0.0 & 7 & 0.6 \\
\hline Total & 16 & 1.3 & 69 & $5 \cdot 8$ & 2 & 0.2 & 87 & $7 \cdot 3$ \\
\hline
\end{tabular}

Table 2 Frequency and type of symptoms reported by symptomatic wheat avoiders ( $n$ 87); CSIRO Food and Health Survey, Australia, December 2010-February 2011

\begin{tabular}{lcc}
\hline & \multicolumn{2}{c}{ Total } \\
\cline { 2 - 3 } & $n$ & $\%$ \\
\hline Bloating or wind & 69 & $79 \cdot 3$ \\
Stomach discomfort or cramps & 48 & $55 \cdot 2$ \\
Feeling sluggish or tired & 32 & $36 \cdot 8$ \\
Constipation & 27 & $31 \cdot 0$ \\
Diarrhoea & 18 & $20 \cdot 7$ \\
Heartburn or indigestion & 14 & $16 \cdot 1$ \\
Skin problems (e.g. itching or rashes) & 12 & $13 \cdot 8$ \\
Mucus build-up & 11 & 12.6 \\
Headaches & 9 & $10 \cdot 3$ \\
Body aches and pains & 7 & $8 \cdot 0$ \\
Sleep disturbances & 6 & 6.9 \\
Feeling anxious or irritable & 6 & 6.9 \\
Vomiting or nausea & 5 & $5 \cdot 7$ \\
Breathing problems (e.g. wheezing) & 5 & $5 \cdot 7$ \\
Feeling sad or blue & 3 & 3.4 \\
Sweating & 2 & 2.3 \\
Feeling restless or hyperactive & 0 & $0 \cdot 0$ \\
Hives & 0 & 0.0 \\
\hline
\end{tabular}

Multiple responses were allowed.

past diagnosis of irritable bowel syndrome (IBS), depression, food sensitivity or food allergy.

Table 4 shows the results of a multivariable logistic regression for the prediction of symptomatic wheat avoidance. Relative to the rest of the sample (minus the fourteen putative coeliac cases), wheat avoidance was significantly predicted by being female, more receptive to complementary medicine and less receptive to conventional medicine. It was not significantly predicted by any of the psychological variables, although a positive association with analytical thinking approached significance. Cross-tabulation of avoidance data revealed that $52.9 \%$ of symptomatic wheat avoiders also reported avoiding dairy products.

Figure 2 shows the rated influence of seven information sources on the decision to avoid wheat products. Ratings of 'very much' ranged from $4.6 \%$ for the Internet to $23.0 \%$ for a naturopath as an influential source.

\section{Discussion}

We believe that this is the first population survey that addresses the issue of wheat avoidance. Several key points emerge from the data. The first is that individuals reporting a diagnosis of coeliac disease formed a very small proportion of those reporting wheat avoidance. Of the $10.7 \%$ of survey respondents (population-weighted by age and gender) who reported avoiding wheat, we classified approximately one-tenth as putative coeliac cases (and outside the scope of the present study) on the basis of claimed diagnoses ( $0.8 \%$ weighted) or reported symptoms ( $0.3 \%$ weighted). Whether our classification of this group is medically appropriate cannot, of course, be verified; however, at $1.1 \%$ overall (weighted), their representation in the sample corresponds closely to an estimate of the prevalence of coeliac disease in Australia based on data from a regional community ${ }^{(8)}$. Also excluded from further study were a number of respondents (2.6\% weighted) who attributed their avoidance of wheat to family needs, weight concerns and more idiosyncratic factors. The remaining group of wheat avoiders, amounting to $7.0 \%$ (weighted) of the sample, attributed a range of adverse symptoms to the consumption of wheat. What is notable about these is the high prevalence of gastrointestinal symptoms, especially bloating or wind, and the almost complete absence of symptoms that might indicate an allergenic response. Fewer than $6 \%$ of these symptomatic wheat avoiders invoked formally diagnosed food sensitivity, and non-medical information sources were prominent among rated influences on the decision to avoid wheat. Symptomatic wheat avoidance was predicted by gender (being female), a lesser receptiveness to conventional medicine and a greater receptiveness to complementary medicine. It was not predicted by a lesser propensity for logical thought or an anxious disposition, either in general or in relation to health; no causal inferences can be drawn from the observation that symptomatic wheat avoiders $(32.9 \%)$ were more likely to indicate a past diagnosis of depression than non-avoiders (19.5\%). Overall, the data indicate that the decision to avoid wheat relies substantially on a non-medically diagnosed connection between ingestion of wheat products and gastrointestinal symptoms. Both the symptoms reported and the lack of diagnosis are important to any attempt to understand this behaviour.

\section{Symptoms and mechanisms}

The pattern of symptoms reported suggests strongly that there is an environmental component involved, but provides 
Table 3 Diagnosed conditions reported by symptomatic wheat avoiders $(n 87)$ and the rest of the sample $(n 1083)$ with cases of suspected coeliac disease excluded; CSIRO Food and Health Survey, Australia, December 2010-February 2011

\begin{tabular}{|c|c|c|c|c|c|c|c|c|}
\hline & \multicolumn{4}{|c|}{ Symptomatic wheat avoidance } & \multirow[b]{2}{*}{$\chi^{2}$} & \multirow[b]{2}{*}{ df } & \multirow[b]{2}{*}{$n$} & \multirow[b]{2}{*}{$P$} \\
\hline & Yes & $\%$ & No & $\%$ & & & & \\
\hline IBS & & & & & $13 \cdot 59$ & 1 & 1129 & $<0.001$ \\
\hline Yes & 17 & $21 \cdot 2$ & 91 & 8.7 & & & & \\
\hline No & 63 & $78 \cdot 8$ & 958 & $91 \cdot 3$ & & & & \\
\hline Depression & & & & & $8 \cdot 47$ & 1 & 1125 & 0.004 \\
\hline Yes & 27 & $32 \cdot 9$ & 203 & $19 \cdot 5$ & & & & \\
\hline No & 55 & $67 \cdot 1$ & 840 & 80.5 & & & & \\
\hline Food sensitivity & & & & & $75 \cdot 85$ & 1 & 1129 & $<0.010$ \\
\hline Yes & 31 & $37 \cdot 8$ & 82 & $7 \cdot 8$ & & & & \\
\hline No & 51 & $62 \cdot 2$ & 965 & $92 \cdot 2$ & & & & \\
\hline Food allergy & & & & & $23 \cdot 14$ & 1 & 1126 & $<0.001$ \\
\hline Yes & 17 & $21 \cdot 0$ & 67 & $6 \cdot 4$ & & & & \\
\hline No & 64 & $79 \cdot 0$ & 978 & 93.6 & & & & \\
\hline Heart disease/stroke & & & & & 0.04 & 1 & 1131 & 0.85 \\
\hline Yes & 10 & $12 \cdot 0$ & 119 & 11.4 & & & & \\
\hline No & 73 & 88.0 & 929 & 88.6 & & & & \\
\hline Diabetes & & & & & 0.04 & 1 & 1133 & 0.85 \\
\hline Yes & 5 & $6 \cdot 0$ & 69 & $6 \cdot 6$ & & & & \\
\hline No & 78 & 94.0 & 981 & 93.4 & & & & \\
\hline Obesity & & & & & 0.59 & 1 & 1122 & 0.44 \\
\hline Yes & 6 & 7.5 & 106 & $10 \cdot 2$ & & & & \\
\hline No & 74 & 92.5 & 936 & $89 \cdot 8$ & & & & \\
\hline Bowel/rectal cancer & & & & & $0.35^{*}$ & 1 & 1129 & 1.00 \\
\hline Yes & 1 & $1 \cdot 2$ & 23 & $2 \cdot 2$ & & & & \\
\hline No & 81 & 98.8 & 1024 & $97 \cdot 8$ & & & & \\
\hline IBD & & & & & $3 \cdot 14^{*}$ & 1 & 1129 & 0.08 \\
\hline Yes & 5 & $6 \cdot 1$ & 28 & $2 \cdot 7$ & & & & \\
\hline No & 77 & 93.9 & 1019 & $97 \cdot 3$ & & & & \\
\hline CFS & & & & & $1 \cdot 19^{*}$ & 1 & 1128 & 0.29 \\
\hline Yes & 4 & 4.9 & 29 & $2 \cdot 8$ & & & & \\
\hline No & 78 & $95 \cdot 1$ & 1017 & $97 \cdot 1$ & & & & \\
\hline Asthma & & & & & $2 \cdot 37$ & 1 & 1125 & $0 \cdot 12$ \\
\hline Yes & 20 & $24 \cdot 1$ & 181 & $17 \cdot 4$ & & & & \\
\hline No & 63 & $75 \cdot 9$ & 861 & $82 \cdot 6$ & & & & \\
\hline
\end{tabular}

IBS, irritable bowel syndrome; IBD, inflammatory bowel disease; CFS, chronic fatigue syndrome.

*Fisher's exact test used when cell frequencies $<5$.

Table 4 Multivariable logistic regression of predictors of symptomatic wheat avoidance; CSIRO Food and Health Survey, Australia, December 2010-February 2011

\begin{tabular}{lrrrrrr}
\hline & & & & & \multicolumn{2}{c}{$95 \% \mathrm{Cl}$ for OR } \\
\cline { 5 - 7 } Predictor & \multicolumn{1}{c}{} & & & & & \\
\hline Sex & -1.36 & 0.30 & $<0.001$ & 0.26 & 0.14 & 0.46 \\
Receptiveness to complementary medicine & 0.52 & 0.12 & $<0.001$ & 1.68 & 1.32 & 2.14 \\
Receptiveness to conventional medicine & -0.50 & 0.11 & $<0.001$ & 0.61 & 0.49 & 0.76 \\
Age & 0.01 & 0.01 & 0.11 & 1.01 & 1.00 & 1.03 \\
Analytical thinking style & 0.30 & 0.16 & 0.06 & 1.35 & 0.99 & 1.84 \\
Intuitive thinking style & 0.14 & 0.17 & 0.40 & 1.15 & 0.83 & 1.60 \\
Neuroticism & -0.20 & 0.20 & 0.31 & 0.82 & 0.55 & 1.21 \\
Illness worry & 0.17 & 0.15 & 0.26 & 1.18 & 0.88 & 1.58 \\
Constant & -3.73 & 1.30 & 0.004 & 0.02 & & \\
\hline
\end{tabular}

no a priori support for undiagnosed coeliac disease or wheat allergy as a factor. The relatively frequent reporting of bloating or wind and cramp indicates disordered large bowel fermentation, which has also been recorded in IBS patients ${ }^{(29)}$. This raises the possibility that the symptoms triggering wheat avoidance are merely an aspect of IBS; indeed, symptomatic wheat avoiders were more than twice as likely as non-avoiders to report a past diagnosis of IBS.
A diagnosis of IBS itself embraces a variety of possible environmental triggers, including dietary factors ${ }^{(13,30)}$, with a discrete group of rapidly fermented dietary carbohydrates, referred to by the acronym FODMAPS ${ }^{(14,31)}$, and food chemical ingestion among those specifically implicated ${ }^{(32)}$. Some of these components may be present in some wheatbased foods, but our data on which foods in particular are being avoided may not be instructive. Those symptomatic 


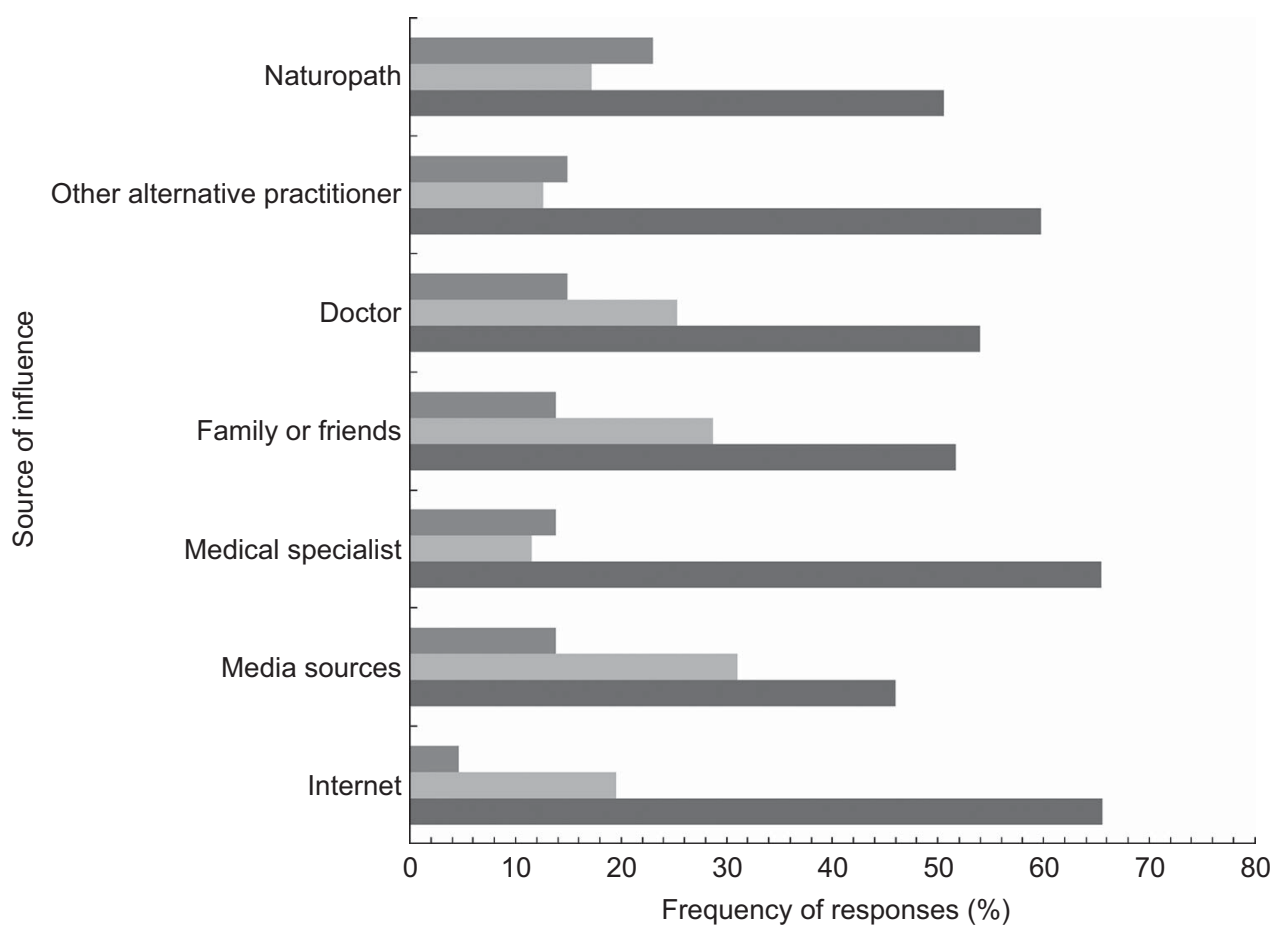

Fig. 2 Extent of influence ( $\square$, 'very much'; , 'somewhat';, , 'not at all') of medical and non-medical sources of recommendations in the decision to avoid wheat products among the symptomatic wheat avoiders ( $n$ 87); CSIRO Food and Health Survey, Australia, December 2010-February 2011

individuals who reported selective avoidance most frequently identified bread; this may reflect the high level of fructans (fructo-oligosaccharides) in wheat flour or merely the ubiquity of bread in the Australian diet. Similar points might be made in respect of the other frequently nominated foods. Nor can we rule out the possible effects of other ingredients. The search for possible mechanisms is likely to be further complicated by evidence that patients may report symptoms of intolerance in the absence of changes in clinical indices (e.g. breath hydrogen) ${ }^{(33,34)}$. Further, while serological and histological markers have been identified that may be able to distinguish between non-coeliac wheat sensitivity, IBS and coeliac disease, wheat sensitivity is a heterogeneous condition comprising various subgroups displaying different clinical characteristics ${ }^{(15)}$.

Findings with clinical populations have associated perceived food sensitivities with psychogenic factors, such as anxiety and negative affect ${ }^{(35,36)}$, in a possible cycle of heightened perception and subsequent misattribution of bodily symptoms ${ }^{(37)}$. Our findings indicate that it would be mistaken to characterise symptomatic wheat avoidance as the behaviour of an overly anxious, intuitive or non-rational subset of the population; nevertheless, the phenomenon has apparent parallels in a widespread tendency for the invocation of allergies and intolerances on the basis of questionable diagnoses, including self-diagnoses ${ }^{(38)}$. Consequently, whereas the study of adverse reactions to wheat is currently well served by attempts to understand non-coeliac gluten intolerance $^{(9,13,14)}$ and wheat sensitivity ${ }^{(15)}$ and indications of the possible roles of non-gluten wheat constituents such as FODMAPS $^{(31)}$ and $\alpha$-amylase/trypsin inhibitors ${ }^{(20)}$ in IBS-like symptoms, it seems unlikely that these will provide a full explanation for symptomatic wheat avoidance.

\section{Diagnosis, self-diagnosis and poly-avoidance}

The relatively few allusions to diagnoses also provide little clue to possible mechanisms. With the decision to avoid wheat-based products influenced substantially by nonmedical sources, few symptomatic wheat avoiders related the practice to management of a specific medical condition and fewer $(5.7 \%)$ to a formally diagnosed food sensitivity. However, a substantial number (38\%) reported that they had at some time been diagnosed with a food sensitivity or food allergy. Perhaps these subsequently identified diagnoses were not considered 'formal' (i.e. medically supported) or perhaps they related to foods other than wheat. In the latter case, we might ask which other foods wheat avoiders could be avoiding and how a diagnosis of sensitivity to one food might come to predict avoidance of another.

It is noteworthy in this context that more than half of symptomatic wheat avoiders also reported avoiding dairy foods. Although we are aware of no other reports of widespread overlap in avoidance of wheat and dairy, a recent New Zealand study found that doctor-diagnosed lactose intolerance was a significant predictor of gluten avoidance (OR 5.2) in children without diagnosed coeliac disease $^{(16)}$. Physiologically, lactose and gluten have in common the fact that each has been associated with IBS-like 
symptoms in sensitive individuals ${ }^{(12,39)}$. There are conceptual links also between gluten and lactose and between wheat and dairy. 'Gluten free' and 'lactose free' are both permitted claims in Australian and New Zealand food standards, and complementary medicine practitioners widely advocate avoidance of wheat and dairy foods. This backdrop of implicit and explicit cautions raises the possibility that the link between wheat avoidance and dairy avoidance is at least partially social-psychological in origin. It suggests the possible operation of simple heuristics by which people classify foods as fundamentally good or $\operatorname{bad}^{(40)}$.

\section{Clinical implications}

Our findings appear to accord with observations that many people with perceived food intolerances do not seek medical advice regarding their symptoms ${ }^{(41)}$, opting either to endure their symptoms or treat themselves ${ }^{(10,41-43)}$, generally by eliminating the foods in question from the $\operatorname{diet}^{(10)}$. This behaviour has a number of clinical and public health implications. Studies of patient groups prescribed exclusion diets - e.g. people with coeliac disease - document the substantial costs of these to both patient quality of life and public health budgets ${ }^{(44,45)}$. A risk for the selfdiagnosed is that the misinterpretation of symptoms may lead to unnecessarily restrictive diets and potentially serious dietary imbalances ${ }^{(46,47)}$. The short-term benefits of alleviating adverse symptoms should be weighed against the long-term health consequences of eliminating dietary factors and their related nutrient profiles. A more critical risk is that self-diagnosis of symptoms as due to a food intolerance may lead to delays in diagnosis and treatment of potentially serious underlying medical conditions.

\section{Strengths and limitations}

Limitations of the present study lie in the inevitable reliance on self-report data. Our data on symptoms, diagnoses and medical conditions are participants' accounts of these, based on their memories and interpretations; substantiation of these is beyond the scope of a population survey, as is the detailed analysis of dietary practices and medical histories. The risk of social desirability bias is lessened here by participant anonymity ${ }^{(48)}$, and embedding the study in an omnibus survey offers enhanced protection against demand characteristics cuing participants to respond in certain ways ${ }^{(49)}$. Strengths of the study lie in the use of a probability sample, drawn from the national population and of sufficient size to permit the study of minority sub-populations, three relatively uncommon characteristics in survey research. Although the response rate of $41 \%$ is substantial for a community survey ${ }^{(50)}$, response rate is a poor index of the representativeness of a sample ${ }^{(51,52)}$. Deviations from the population distribution of age and gender were identified and adjusted for, but this does not rule out the possibility of sampling bias in favour of people with an interest in food or health. We can draw some comfort, however, from the correspondence between estimates of potential prevalence of coeliac disease based on our national survey data $(1.1 \%)$ and the comprehensive screening of a community cohort $(0.96 \%)^{(8)}$.

\section{Future directions}

At the population level, a prevalence of ostensibly noncoeliac symptomatic wheat avoiders of $7.0 \%$ translates to more than 1 million Australian adults. Even allowing for some inflation through sampling bias, this makes wheat avoidance a significant public health matter. Our data raise important questions for medical practitioners and allied health professionals who may well be unaware that their patients may be avoiding important mainstream foods. The fact that symptomatic wheat avoidance appears to occur overwhelmingly as part of a self-prescribed elimination diet indicates the need for an intensive investigation of the experiences that have led a significant segment of the population to embark upon such a path.

The findings point to a number of other directions for further research. One of these, as in the case of coeliac patients, is the question of the nutritional adequacy of the diet in the absence of wheat products, especially dietary fibre, B-vitamins and iron ${ }^{53,54)}$. Another is the study of physiological mechanisms capable of explaining why some people might experience certain symptoms on consumption of particular food components commonly found in wheatbased products and other foods. A third is the extent and nature of poly-avoidances, which add to the potential for nutritional imbalances and complicate the already difficult task of identifying a specific food component as the source of symptoms, let alone a physiological mechanism. Also of interest in this context is whether, where multiple foods are avoided, their elimination was undertaken incrementally or simultaneously, with any perceived benefits attributed to a change of diet in general rather than any aspect of the diet specifically. A final question concerns the relationship between the avoidance of wheat, as examined here, and the apparently widespread avoidance of gluten, at least as reflected in the demand for gluten-free foods and the interest of researchers in a non-coeliac sensitivity to gluten. The fact that so few symptomatic wheat avoiders nominated gluten as the critical agent in their symptoms cautions against the assumption that the factors associated with wheat avoidance substantially explain the avoidance of gluten.

\section{Conclusions}

Our findings show that a significant proportion of the ostensibly non-coeliac Australian adult population, predominantly female, is avoiding the consumption of wheatcontaining products. This behaviour is associated with physiological symptoms that are largely of gastrointestinal origin, may also include tiredness, but exclude signs of allergy. Although its origins appear to fall largely outside 
mainstream medicinal practice, wheat avoidance is not a behaviour to be dismissed as the product of anxious or illogical reasoning. As a dietary behaviour that is apparently already practised in a great number of households in Australia and is a matter of concern in many other countries, wheat avoidance looms as a significant public health issue in urgent need of closer investigation. There is a pressing need to establish the physiological basis or bases for the practice and to determine the consequences for nutrient intakes in those people affected. Whatever the physiological mechanism(s), it is noteworthy that the practice consistently occurs in the absence of a formal medical diagnosis. This makes it of added interest both as a model for avoidance of other foods and for what it may reveal about contemporary health-related diagnostic and decision processes. It is possible that the elimination of foods deemed to be suspect on some grounds is part of a more general public health trend towards self-diagnosis and self-management of symptoms.

\section{Acknowledgements}

Financial support: This study was part of a larger project conducted with financial assistance from the Grains Research and Development Corporation. The funding body had no involvement in the design of the study, collection, analysis or interpretation of the data, writing of the report or the decision to submit the article for publication. Conflict of interest: None. Authorship: All authors were involved in the conceptualisation of the study and critical revision of the manuscript. P.M., S.G. and N.C. designed and conducted the study. S.G. conducted data analysis. P.M. and S.G. drafted the manuscript. All authors had full access to all of the data and can take responsibility for the integrity of the data and the accuracy of the data analysis. Ethics of buman subject participation: The study was conducted according to the guidelines laid down in the Declaration of Helsinki and all procedures involving human subjects were approved by the CSIRO Human Research Ethics Committee.

\section{References}

1. Pascoe DA \& Fulcher RG (2007) Biochemistry and compartmentalization of cereal grain components and their functional relationship to mammalian health. Whole Grains Health, pp. 89-114 [L Marquart, DR Jacobs, GH McIntosh, et al., editors]. Ames, IA: Blackwell Publishing Professional.

2. Baghurst PA, Baghurst KI \& Record SJ (1996) Dietary fibre, non-starch polysaccharides and resistant starch: a review. Food Aust 48, S1-S35.

3. Kilmartin C, Wieser H, Abuzakouk M et al. (2006) Intestinal T cell responses to cereal proteins in celiac disease. Dig Dis Sci 51, 202-209.

4. Anand BS, Piris J \& Truelove SC (1978) The role of various cereals in coeliac disease. QJ Med 47, 101-110.

5. Scanlon SA \& Murray JA (2011) Update on celiac disease etiology, differential diagnosis, drug targets, and management advances. Clin Exp Gastroenterol 4, 297-311.
6. Shewry PR (2009) Wheat. J Exp Bot 60, 1537-1553.

7. Inomata N (2009) Wheat allergy. Curr Opin Allergy Clin Immunol 9, 238-243.

8. Chin MW, Mallon DF, Cullen DJ et al. (2009) Screening for coeliac disease using anti-tissue transglutaminase antibody assays, and prevalence of the disease in an Australian community. Med J Aust 190, 429-432.

9. Sapone A, Bai JC, Ciacci C et al. (2012) Spectrum of glutenrelated disorders: consensus on new nomenclature and classification. BMC Med 10, 13.

10. Biesiekierski JR, Newnham ED, Shepherd S et al. (2011) Self-diagnosis of non-coeliac gluten intolerance by Australian adults: failure to exclude coeliac disease or benefit from a gluten-free diet. J Gastroenterol Hepatol 26, 70.

11. Vinning G \& McMahon G (2006) Gluten-Free Grains: A Demand-and-Supply Analysis of Prospects for the Australian Health Grains Industry. Canberra: Australian Government, Rural Industries Research and Development Corporation.

12. Biesiekierski JR, Newnham ED, Irving PM et al. (2011) Gluten causes gastrointestinal symptoms in subjects without celiac disease: a double-blind randomized placebocontrolled trial. Am J Gastroenterol 106, 508-514.

13. Verdu EF, Armstrong D \& Murray JA (2009) Between celiac disease and irritiable bowel syndrome: the 'No Man's Land' of gluten sensitivity. Am J Gastroenterol 104, 1587-1594.

14. Di Sabatino A \& Corazza GR (2012) Nonceliac gluten sensitivity: sense or sensibility? Ann Intern Med 156, 309-311.

15. Carroccio A, Mansueto P, Iacono G et al. (2012) Non-celiac wheat sensitivity diagnosed by double-blind placebo-controlled challenge: exploring a new clinical entity. $\mathrm{Am} \mathrm{J}$ Gastroenterol 107, 1898-1906.

16. Tanpowpong P, Ingham TT, Lampshire PK et al. (2012) Coeliac disease and gluten avoidance in New Zealand children. Arch Dis Child 97, 12-16.

17. Catassi C, Bai J, Bonaz B et al. (2013) Non-celiac gluten sensitivity: the New Frontier of gluten related disorders. Nutrients 5, 3839-3853.

18. Shepherd S, Parker FC, Muir JG et al. (2008) Dietary triggers of abdominal symptoms in patients with irritable bowel syndrome: randomized placebo-controlled evidence. Clin Gastroenterol Hepatol 6, 765-771.

19. Biesiekierski JR, Peters SL, Newnham ED et al. (2013) No effects of gluten in patients with self-reported non-celiac gluten sensitivity following dietary reduction of lowfermentable, poorly-absorbed, short-chain carbohydrates. Gastroenterology 145, 320-328.

20. Junker Y, Zeissig S, Kim S-J et al. (2012) Wheat amylase trypsin inhibitors drive intestinal inflammation via activation of toll-like receptor 4. J Exp Med 209, 2395-2408.

21. Goldberg LR, Johnson JA, Eber HW et al. (2006) The international personality item pool and the future of publicdomain personality measures. J Res Pers 40, 84-96.

22. Epstein S, Pacini R, Denes-Raj V et al. (1996) Individual differences in intuitive-experiential and analytical-rational thinking styles. J Pers Soc Psychol 71, 390-405.

23. Cacioppo JT \& Petty RE (1982) The need for cognition. J Pers Soc Psychol 42, 116-131.

24. Pilowsky I (1967) Dimensions of hypochondriasis. $\mathrm{BrJ}$ Psychiatry 113, 89-93.

25. Barsky AJ, Cleary PD, Wyshak G et al. (1992) A structured diagnostic interview for hypochondriasis: a proposed criterion standard. J Nerv Ment Dis 180, 20-27.

26. Tabachnick BG \& Fidell LS (1996) Using Multivariate Statistics. New York: Harper Collins.

27. Little RJA (1988) A test of missing completely at random for multivariate data with missing values. J Am Stat Assoc 83, 1198-1202. 
28. Siegel S (1956) Nonparametric Statistics for the Behavioral Sciences. New York: McGraw-Hill Book Company, Inc.

29. King TS, Elia M \& Hunter JO (1998) Abnormal colonic fermentation in irritable bowel syndrome. Lancet 352, $1187-1189$.

30. Staudacher HM, Whelan K, Irving PM et al. (2011) Comparison of symptom response following advice for a diet low in fermentable carbohydrates (FODMAPs) versus standard dietary advice in patients with irritable bowel syndrome. J Hum Nutr Diet 24, 487-495.

31. Gibson PR \& Shepherd SJ (2012) Food choice as a key management strategy for functional gastrointestinal symptoms. Am J Gastroenterol 107, 657-666.

32. Barrett JS \& Gibson PR (2012) Fermentable oligosaccharides, disaccharides, monosaccharides and polyols (FODMAPs) and nonallergic food intolerance: FODMAPs or food chemicals? Therap Adv Gastroenterol 5, 261-268.

33. Yang J, Deng Y, Chu H et al. (2013) Prevalence and presentation of lactose intolerance and effects on dairy product intake in healthy subjects and patients with irritable bowel syndrome. Clin Gastroenterol Hepatol 11, 262-268.

34. Yao CK, Tan HL, Van Langenberg DR et al. (2011) Abnormal intestinal handling of sorbitol and mannitol in patients with IBS: mechanistic insights and potential clinical implications. J Gastroenterol Hepatol 26, 70.

35. Lillestol K, Berstad A, Lind R et al. (2010) Anxiety and depression in patients with self-reported food hypersensitivity. Gen Hosp Psychiatry 32, 42-48.

36. Pearson DJ, Rix KJB \& Bentley SJ (1983) Food allergy - how much in the mind - a clinical and psychiatric-study of suspected food hypersensitivity. Lancet 1, 1259-1261.

37. Rief W \& Broadbent E (2007) Explaining medically unexplained symptoms - models and mechanisms. Clin Psychol Rev 27, 821-841.

38. Stein K (2009) Are food allergies on the rise, or is it misdiagnosis? J Am Diet Assoc 109, 1832-1837.

39. Vesa TH, Seppo LM, Marteau PR et al. (1998) Role of irritable bowel syndrome in subjective lactose intolerance. Am J Clin Nutr 67, 710.

40. Rozin P, Ashmore M \& Markwith M (1996) Lay American conceptions of nutrition: dose insensitivity, categorical thinking, contagion, and the monotonic mind. Health Psychol 15, 438-447.
41. McGowan M \& Gibney MJ (1993) Calcium intakes in individuals on diets for the management of cows milk allergy a case-control study. Eur J Clin Nutr 47, 609-616.

42. Young E, Stoneham MD, Petruckevitch A et al. (1994) A population study of food intolerance. Lancet 343, 1127-1130.

43. Rona R \& Chinn S (1987) Parents' perceptions of food intolerance in primary school children. BMJ 294, 863-866.

44. Long KH, Rubio-Tapia A, Wagie AE et al. (2010) The economics of coeliac disease: a population-based study. Aliment Pharmacol Ther 32, 261-269.

45. Hallert C, Granno C, Grant C et al. (1998) Quality of life of adult coeliac patients treated for 10 years. Scand J Gastroenterol 33, 933-938.

46. Teufel M, Biedermann T, Rapps N et al. (2007) Psychological burden of food allergy. World $J$ Gastroenterol 13, 3456-3465.

47. Monsbakken KW, Vandvik PO \& Farup PG (2005) Perceived food intolerance in subjects with irritable bowel syndrome - etiology, prevalence and consequences. Eur J Clin Nutr 60, 667-672.

48. Paulhus DL (1984) Two-component models of socially desirable responding. J Pers Soc Psychol 46, 598-609.

49. Orne MT (1962) On the social-psychology of the psychological experiment - with particular reference to demand characteristics and their implications. Am Psychol 17, 776-783.

50. Sinclair M, O’Toole J, Malawaraarachchi M et al. (2012) Comparison of response rates and cost-effectiveness for a community-based survey: postal, internet and telephone modes with generic or personalised recruitment approaches. BMC Med Res Methodol 12, 132.

51. Hox JJ \& Deleeuw ED (1994) A Comparison of nonresponse in mail, telephone, and face-to-face surveys - applying multilevel modeling to metaanalysis. Qual Quant 28, 329-344.

52. Groves RM (2006) Nonresponse rates and nonresponse bias in household surveys. Public Opin $Q$ 70, 646-675.

53. Thompson T, Dennis M, Higgins LA et al. (2005) Gluten-free diet survey: are Americans with coeliac disease consuming recommended amounts of fibre, iron, calcium and grain foods? J Hum Nutr Diet 18, 163-169.

54. Wild D, Robins GG, Burley VJ et al. (2010) Evidence of high sugar intake, and low fibre and mineral intake, in the glutenfree diet. Aliment Pharmacol Ther 32, 573-581. 